\title{
La aplicación del enfoque de derechos humanos a los fenómenos de población: oportunidades y desafíos
}

\author{
Marcela Ferrer
}

\section{RESUMEN}

Aunque la aplicación de los derechos humanos a los fenómenos de población no es un tema novedoso, hasta ahora no ha sido abordado con gran profundidad en América Latina y el Caribe. Este artículo discute el significado de esta aplicación desde una perspectiva latinoamericana. El trabajo está estructurado en cuatro partes. La primera plantea brevemente qué se entiende por derechos humanos. La segunda describe el sistema internacional de derechos humanos y sus instrumentos. La tercera reflexiona sobre las intersecciones de los fenómenos de población, desarrollo y derechos humanos. Finalmente, la cuarta parte discute las principales oportunidades y desafíos que plantea la aplicación del enfoque de derechos humanos a los fenómenos de población.

Palabras Clave: Derechos Humanos, Población, Desarrollo

\section{ABSTRACT}

The application of the human rights to population's issues is not a new topic, but up to now it has not been deeply used in Latin America and the Caribbean. This article discusses the meaning of this application from a Latin American perspective. The work is structured in four parts. The first one briefly outlines what is understood as human rights. The second one describes the international system of human rights and its instruments. The third one describes the relationships between population's phenomena, development and human rights. Finally, the fourth part discusses the main opportunities and challenges that the application of human rights to population's phenomena outlines.

Keywords: Human Rights, Population, Development.

\footnotetext{
* Marcela Ferrer Departamento de Sociología Universidad de Chile mferrer@uchile.cl 


\section{INTRODUCCIÓN}

Aunque el imaginario colectivo alberga distintas visiones sobre el significado de los derechos humanos, referirse a ellos remite obligadamente al trabajo de las Naciones Unidas. Su acta de fundación establece que la Organización promoverá “el respeto universal a los derechos humanos y a las libertades fundamentales de todos, sin hacer distinción de raza, sexo, idioma o religión". Este fue el primer paso para definir un sistema internacional para la protección de los derechos humanos, que representa sin duda uno de los mayores logros de la humanidad en el siglo XX. Para nadie es novedad, sin embargo, que la implementación real del sistema internacional de derechos humanos ha estado lejos de la ideal. La misma Naciones Unidas reconoció esta tarea pendiente al cumplir 50 años. Por ello, su Programa de Reforma definió que una de las esferas prioritarias debía ser la ampliación de las actividades relacionadas con los derechos humanos, "mediante la reorganización y reestructuración de la secretaría de derechos humanos e integración de los derechos humanos en todas las actividades y programas importantes de las Naciones Unidas" (Naciones Unidas, 1997). Desde entonces, las distintas agencias de la Organización han tomado diversas medidas para incorporar el enfoque de derechos humanos en sus actividades, y para lograr que los gobiernos respeten la legislación internacional de derechos humanos e incorporen el enfoque en sus políticas públicas. La aplicación del enfoque de derechos humanos a los fenómenos de población es parte de este llamado, que en la región de América Latina y el Caribe ha sido liderado por el CELADE-División de Población de la CEPAL.

No obstante el "rescate" del paradigma de los derechos humanos desde las Naciones Unidas, la aplicación del enfoque de derechos humanos a los fenómenos de población no es un tema nuevo. La Conferencia Mundial de Población de Bucarest (1974) estableció que la planificación de la familia es un derecho fundamental de todas las parejas e individuos, derecho que ya había sido reconocido en la Conferencia Internacional sobre Derechos Humanos de Teherán (1968). Más tarde, la Conferencia Internacional sobre la Población y el Desarrollo (CIPD), realizada en El Cairo en 1994, consagró la inclusión del enfoque de derechos humanos a los fenómenos de población. En especial, legitimó el concepto de derechos reproductivos, pero avanzó mucho más allá de estos derechos. Basta con hacer una re-lectura del Plan de Acción para encontrar alusiones constantes a la necesidad de conciliar las tendencias de la población y el desarrollo sustentable, cautelando el respeto por los derechos humanos ${ }^{1}$.

Aunque los derechos humanos no representan un tema novedoso en el campo de la población y el desarollo, su comprensión, contenidos y desafíos constituyen una enorme tarea. Por ejemplo, la visión de la planificación familiar desde los derechos humanos alude, fundamentalmente, a las tensiones entre individuo-Estado o individuo-sociedad, producidas cuando los intereses sociales o del Estado

${ }^{1}$ Véase Ferrer (2005), páginas 48-52. 
entran en contradicción con los intereses individuales; en este caso, la tensión entre la necesidad de controlar el crecimiento de la población, y el derecho de las mujeres, y/o las parejas, a tomar decisiones libres e informadas respecto de su propia reproducción. Esta discusión está lejos de ser un asunto sencillo. Se trata de conciliar los intereses sociales orientados al bienestar del grupo (por ejemplo, una adecuada relación población-recursos o el poblamiento de áreas de baja densidad poblacional con fines de ejercer soberanía) con los intereses individuales orientados a la autodeterminación de los individuos en tanto seres autónomos (como la decisión de tener hijos o no tenerlos). En definitiva, el problema de conciliar principios macro-éticos y micro-éticos, dilema permanente para los tomadores de decisiones de política pública.

La intersección de los derechos humanos y los fenómenos de población no sólo se ha producido en relación con el control de la fecundidad. Se ha aplicado también a la mortalidad, principalmente en relación con el derecho a la salud. Más recientemente, ciertas temáticas sociodemográficas han cobrado importancia por su vinculación con situaciones de vulnerabilidad, directamente conectadas con los derechos humanos. Tal es el caso del envejecimiento, la salud reproductiva, la equidad de género, la pobreza y los pueblos originarios. En forma paralela, el interés por las intersecciones de la migración internacional y los derechos humanos ha aumentado considerablemente, sobre todo por los efectos de la globalización y la situación de vulnerabilidad, desprotección y discriminación que enfrentan muchos inmigrantes en los países desarrollados y en desarrollo.

Las intersecciones de los derechos humanos y los fenómenos de población y desarrollo tampoco son un tema nuevo en el campo de los derechos humanos. Han sido abordados en diversos instrumentos de legislación internacional y en varios foros internacionales. Incluso, el tratado internacional más reciente está destinado a definir y proteger los derechos humanos de los migrantes internacionales ${ }^{2}$.

No obstante la experiencia acumulada desde el campo de la población y el desarrollo, y desde los derechos humanos, es necesario admitir que estas intersecciones no han sido abordadas con gran profundidad en América Latina y el Caribe, tanto en el ámbito académico y de las organizaciones internacionales, como en el terreno de las decisiones de política.

Este documento discute el significado de la aplicación del enfoque de derechos humanos a los fenómenos de población. El trabajo está estructurado en cuatro partes. La primera plantea brevemente qué se entiende por derechos humanos. La segunda describe el sistema internacional de derechos humanos y sus instrumentos. La tercera reflexiona sobre las intersecciones de los fenómenos de población, desarrollo y derechos humanos. Finalmente, la cuarta parte discute las principales oportunidades y desafíos que plantea la aplicación del enfoque de derechos humanos a los fenómenos de población.

\footnotetext{
${ }^{2}$ Convención Internacional sobre la Protección de los Derechos de todos los Trabajadores Migratorios y sus Familiares (MWC). Aprobado por la Asamblea General de Naciones Unidas en 1990, entrando en vigor en el 2003.
} 


\section{¿QUÉ SON LOS DERECHOS HUMANOS?}

Una cuestión esencial para discutir la aplicación del enfoque de derechos humanos a los fenómenos de población, es definir previamente qué se entiende por derechos humanos y cuál ha sido la construcción histórica y social del concepto. El siguiente apartado discute brevemente estos aspectos.

\section{Los orígenes y fundamentos del concepto}

La expresión "derechos humanos" alude a un conjunto de garantías universales que cada individuo puede reclamar por el solo hecho de formar parte de la especie humana o, como establece la Declaración Universal de 1948, de la familia humana. La noción de derechos humanos es de larga data y ha tenido distintas orientaciones. Por referirse a la "especie humana", la formulación actual de los derechos humanos pretende constituir el único marco ético susceptible de traspasar las diferencias culturales, en un mundo que se divide cotidianamente entre la homogeneidad y la diferencia. Esto abre la pregunta sobre la legitimidad del enfoque de los derechos humanos como marco ético universal, cuyo abordaje excede los límites de este trabajo ${ }^{3}$.

La noción de igualdad entre los integrantes de la especie humana ha estado presente durante gran parte de la historia de la humanidad. Hasta el siglo XVII se plasmó en documentos de distintas religiones. Los siglos XVIII y XIX dieron paso a las luchas laicas por los derechos humanos, iniciadas por la Revolución Francesa (PNUD, 2000). En esos años ya se contaba con importantes documentos que los definían y reclamaban ${ }^{4}$. Sin embargo, las declaraciones estadounidenses (1776 y 1789) y la francesa (1789) son especialmente importantes, puesto que proclamaban con fuerza un nuevo concepto de "hombre" y sociedad (Cassese, 1993).

El concepto de derechos humanos lleva implícita la idea de una sociedad compuesta de individuos libres e iguales. Para el filósofo belga Gilbert Hottois (2000), la expresión paradigmática de los derechos humanos es la Declaración Universal de los Derechos del Hombre y del Ciudadano (1789), originada en tres fuentes: la naturaleza, dios y la razón. Esta tríada, que caracteriza la Declaración de 1789 y el pensamiento de la Modernidad, se atenuó en el siglo xx debido al contexto multicultural en que el discurso de los derechos humanos debía afirmarse. La noción de "dignidad humana" se erigió como el único fundamento capaz de traspasar las fronteras culturales. Sin embargo, esta noción ha sido cuestionada por varios autores y constituye el centro de un debate abierto 5 . Puede utilizarse como fundamento siempre y cuando no se defina el significado de la dignidad, lo cual varía de una cultura a otra. Por ello, a partir de 1948 los derechos humanos

${ }^{3}$ Véase, por ejemplo, Carroza (2003); Cassese (1993); Hottois (2000); Moravcsik (1998); Murgueza (2004).

4 Tal es el caso de los ingleses "Magna Charta" de 1215 y el "Bill of Rights" de 1689.

5 Véase, por ejemplo, Macklin, R., "Reflection on the Human Dignity Symposium: Is dignity a useless concept?", Journal of Palliative Care, Tomo 20, No 3, Toronto, otoño del. 2004. 
son objeto de un consenso regulador, pero no tienen un fundamento sustancial común. Las implicaciones de esta transformación, que Hottois denomina plurifundacionalista abierta del estatuto filosófico de los derechos humanos, es central para entender la perspectiva de los derechos humanos. El consenso sobre ellos no se basa en una naturaleza inmutable y reconocida por todos. Por el contrario, permite definir aquí y ahora, y durante una duración indeterminada que dependerá de la evolución de las condiciones sociales, una cierta naturaleza humana, como también las normas que le corresponden. La filosofía sobre los derechos humanos desarrollada a partir de 1948 se basa en un acuerdo establecido entre los seres humanos. Por lo tanto, está abierta al debate y sujeta a reconsideración frente a nuevos hechos o circunstancias.

\section{-El significado actual del concepto de derechos humanos}

Aunque se habla reiteradamente de los derechos humanos, pocos se detienen a explicitar su significado. Su utilización pareciera basarse en un consenso implícito respecto de sus dimensiones, o de los fenómenos a los cuales puede ser aplicado. Esto no es privativo del concepto de derechos humanos. Ocurre con la mayoría de los conceptos relacionados con aspiraciones sociales o modelos de sociedad, que traspasan el campo disciplinario para instalarse en el lenguaje cotidiano. Algunos ejemplos son los conceptos de democracia, solidaridad y justicia. Se coincide en el deseo de sociedades más democráticas, más solidarias y más justas. Se coincide menos al momento de especificar qué tipo de democracia se quiere, cuál es el límite de la solidaridad y qué criterio de justicia debemos utilizar.

Exigir el respeto a los derechos humanos se ha convertido en un lugar común, tanto de documentos internacionales y nacionales como de acciones de las organizaciones de la sociedad civil. Partidarios de distintas tendencias políticas utilizan el discurso de los derechos humanos como una herramienta política, pudiendo incluso ser empleado para promover o rechazar la misma causa (Sumner, 2001). Esto es recurrente, por ejemplo, en el caso del aborto inducido. Quienes defienden su legalización plantean que es una opción fundamentada en el derecho de las mujeres a la autonomía e integridad corporal y, en situaciones de riesgo vital, en el derecho de las mujeres a la vida; quienes se oponen afirman que el aborto niega el derecho a la vida del no nacido ${ }^{6}$. Es importante consignar, sin embargo, que la

${ }^{8}$ Véase Warren, M. A. (2002), "On the moral and legal status of abortion”, en LaFollete (2002), Ethics in Practice, Massachusetts, Blackwell Publishers Limited, pp. 63-72; Singer, P. (2002), "XIII. Quitar la vida: el embrión y el feto" (de Ética Práctica), en Una vida ética. Escritos, España, Taurus Pensamiento, pp. 179-198.

9 La Convención Americana de Derechos Humanos, conocida como "Pacto de San José", establece la protección de la vida, en general, desde el momento de la concepción (artículo 4). Sin embargo, la Comisión Interamericana de Derechos Humanos señaló en el caso "Baby Boy versus USA" que el término "en general" matiza la protección de la vida desde el momento de la concepción, concluyendo que la Convención no requiere que los Estados prohíban el aborto. Véase Katzive, Laura y Anika Rahman (2000), Abortion and human rights. New York, CRLP, citado en IPAS (2003) "Los derechos humanos, el embarazo no deseado y la atención relacionada con el aborto. Información de referencia y casos ilustrativos”. Julio 2003. 
legislación internacional de derechos humanos reconoce los derechos de los seres humanos, y no reconoce derecho alguno a los fetos o no natos ${ }^{7}$.

No sólo se utiliza el discurso de los derechos humanos para defender o rechazar la misma causa. Tanto activistas como estudiosos del tema utilizan significados que se superponen: algunos emplean el concepto como un conjunto de obligaciones de la legislación internacional, otros lo hacen para señalar ciertos estándares éticos que acentúan la importancia de los intereses individuales, y otros utilizan el lenguaje de los derechos humanos por sus cualidades aspiracionales o retóricas (Gostin, 2001). La idea de que los derechos humanos tienen una especial importancia moral ha producido "que cualquiera que pretende hoy el respeto de cualquiera de sus deseos, la protección de cualquiera de sus intereses o la satisfacción de cualquiera de sus necesidades, prefiere formularlos como 'derechos' que asumir la costosa carga de demostrar por qué sus deseos han de ser respetados, sus intereses protegidos o sus necesidades satisfechas" (Hierro, 2002, pp. 35-36). En palabras del autor, esto ha conducido a una verdadera "inflación de los derechos humanos": además de los derechos individuales, se habla de los derechos sociales o de segunda generación, como también de los derechos de tercera y cuarta generación; se alude a los derechos en condiciones específicas (mujeres, niños, discapacitados y otros), a los derechos de colectivos (pueblos, etnias), de los no nacidos, de las generaciones futuras, de los animales e incluso de la naturaleza. En síntesis, la popularidad del discurso de los derechos humanos ha resultado en una considerable imprecisión del concepto.

No obstante su relación con una considerable imprecisión del concepto, es evidente que la popularidad del lenguaje de los derechos humanos ha permitido sensibilizar a vastos sectores sociales. Sin embargo, se ha vuelto también su gran amenaza: la facilidad con que se adapta a todos los discursos puede hacer que, al servir para justificar todo, termine justificando nada. Siguiendo a Sumner (2001), para que el discurso de los derechos humanos se transforme en una herramienta efectiva, es necesario ir más allá de la retórica o la mera declaración, lo que implica explicitar el contenido del derecho, justificar por qué debe satisfacerse, identificar al sujeto o portador de ese derecho, y a un agente que deba satisfacer esa exigencia, es decir, cumplir determinados deberes.

A lo anterior se suma una cuestión central: el reconocimiento legal del derecho. Decir que existe el derecho a la atención de salud puede tener, al menos, dos significados. Primero, que tal derecho existe por ley. Segundo, que todos los seres humanos deben tener acceso a la atención de salud en virtud del principio de justicia (Gostin, 2003). Ambos significados no son excluyentes, pues el primero implica el reconocimiento del segundo. Situación similar ocurre con los derechos reproductivos. Puede argumentarse su existencia por su reconocimiento en la CIPD o en la $\mathrm{CEDAW}^{8}$, o en función de principios éticos como el respeto a la autonomía de las personas. En principio, ambos significados apuntan en la dirección correc-

${ }^{8}$ Convención para la eliminación de todas las formas de discriminación contra la mujer. CEDAW (por sus siglas en inglés). 
ta, pues aluden a dos dimensiones de los derechos humanos, la legal y la moral. Esto es similar a lo que Wellman (1995) denomina derechos institucionales y derechos morales ${ }^{9}$. Sin embargo, la ausencia de claridad respecto a la distinción entre los derechos que son reconocidos por ley y los que no lo son, confunde las acciones orientadas a la defensa y protección de los derechos humanos. Más aún, para algunos autores (Muguerza, 2004) los derechos humanos existen como tales sólo cuando son reconocidos en la legislación, de lo contrario corresponden únicamente a "exigencias morales".

Para ir más allá de la retórica se necesita poner atención en qué se entiende por derechos humanos (contenido, fundamento, portador y agente), cómo son definidos en términos legales y cuáles de estos derechos están consignados en la legislación nacional e internacional. Para ello es preciso considerar dos cuestiones centrales: que sólo algunos derechos han sido reconocidos legalmente, es decir, antes fueron exigencias morales, y que el reconocimiento legal de ciertos derechos es un primer paso para su garantía, pero no asegura que sean promovidos y garantizados. Sin ánimo de judicializar el tema, el discurso sobre los derechos humanos necesita reconocer explícitamente ambos planos. Esto, porque aunque es claro que las relaciones entre legislación y moral no son sincrónicas, la exigibilidad legal tiene mayor fuerza que la exigibilidad moral. Existen diversos instrumentos internacionales de derechos humanos, muchos de ellos de carácter vinculante, que abarcan una diversidad de ámbitos cruciales para la vida en sociedad. Han sido ratificados por un número importante de países, muchos de los cuales han incorporado disposiciones explícitas en sus Constituciones.

La distinción anterior no postula una diferencia sustantiva entre derechos humanos y derechos reconocidos por ley. Sólo tiene fundamentos prácticos y de acción política, puesto que los derechos humanos son una construcción humana que responde a ciertos condicionantes históricos. Basta pensar en hitos tan relevantes como la Carta de los Derechos del Hombre y del Ciudadano, fruto de la Revolución Francesa, y las Cartas incorporadas a las Constituciones de los Estados Unidos recién independizados, que fueron la expresión del triunfo de grupos que se sentían excluidos del consenso hasta entonces vigente. Incluso, el nuevo orden resultante de ambas revoluciones fue excluyente de otros grupos humanos, como los esclavos en los Estados Unidos y los campesinos, obreros y mujeres en la Francia post revolucionaria (Muguerza, 2004). El sufragio universal femenino en Francia fue logrado recién finalizada la Segunda Guerra Mundial, más de 150 años después del triunfo de la Revolución Francesa. En contraste, el sufragio masculino universal se consiguió en 1848, casi cien años antes que el femenino y sólo 59 años después de la Declaración (Ballarín y otros, 1997). El siglo xx, de-

${ }^{9}$ Los primeros son conferidos por una organización o convención social, en tanto los segundos por fundamentos morales, independientemente de las creencias o prácticas humanas. El tipo más importante de derechos institucionales es el de los derechos legales consagrados en algún sistema legislativo, mientras que el de los morales es el de los derechos humanos (tradicionalmente llamados derechos naturales), que una persona posee por el sólo hecho de ser humano, independientemente de que sea reconocido por las instituciones de una sociedad. 
nominado por el cientista político italiano Norberto Bobbio como el siglo de los derechos, expandió estos derechos a toda la especie humana, mediante la promulgación de la Declaración Universal de Derechos Humanos y los instrumentos que la precedieron. Los derechos humanos reconocidos en tales instrumentos son producto de consensos que responden a condiciones históricas, políticas, culturales y económicas; se vinculan a un momento y lugar determinados. Por ello, pueden estar sujetos a constante revisión y redefinición, lo que incluye, por supuesto, la creación de nuevos instrumentos.

\section{EL SISTEMA INTERNACIONAL DE DERECHOS HUMANOS Y SUS INSTRUMENTOS}

La legislación internacional de derechos humanos comprende una serie de instrumentos creados como respuesta a los atentados contra la paz y la humanidad producidos durante la Segunda Guerra Mundial ${ }^{10}$. Comenzó con la Carta de las Naciones Unidas de 1945, derivando en una serie de instrumentos y de organismos que supervisan el cumplimiento de los acuerdos. Aunque se han realizado considerables avances en el plano legal, es importante recordar que la legislación en derechos humanos es letra muerta si no se cuenta con un justo sistema de administración de justicia al interior de los países (PNUD 2000).

Los instrumentos internacionales de derechos humanos más importantes son los tratados, pactos o convenciones, que corresponden a acuerdos jurídicamente obligatorios entre Estados. La firma presidencial de los mismos es la primera medida que adoptan los Estados, y representa su promesa de apoyarlos y ceñirse a sus normas jurídicas, pero no implica deberes jurídicos. Estos se adquieren cuando la firma es ratificada por el Parlamento, convirtiéndolo de este modo en Estado parte de esa herramienta normativa.

Los instrumentos hacen hincapié en principios y obligaciones que garantizan que el proceso de realización de los derechos comprenda: no discriminación, progreso adecuado, participación verdadera y acceso a un recurso efectivo ante los tribunales nacionales competentes en caso de violación de alguno de los derechos humanos reconocidos por ley (PNUD, 2000). Habitualmente, las obligaciones se refieren a los deberes de respetar, proteger, promover y realizar o hacer efectivos los derechos incluidos en el pacto, tratado o convenio. Cada una de estas responsabilidades jurídicas puede implicar obligaciones más específicas relacionadas con la conducta, ya sea acción u omisión, como también con los resultados esperados (Artigas, 2001). Por ejemplo, la de respetar es una obligación negativa,

10 Esta no fue la primera vez que se trató de desarrollar una protección universal de los derechos humanos. Cassese (1993) señala dos intentos previos. El primero, en 1919, en ocasión de la redacción del Pacto de la Sociedad de las Naciones. Japón solicitó que se incluyera una disposición que asegurara un trato igual y justo a todos los extranjeros que tuvieran la ciudadanía de un Estado miembro de la Sociedad. El segundo, en 1933, originado en el reclamo de discriminación racial que efectuó un ciudadano alemán de origen hebreo al Consejo de la Sociedad de las Naciones. Ambos intentos fracasaron.

8 
inmediata y sin costo. La obligación de proteger puede ser positiva o negativa, poco costosa e inmediata. Sin embargo, la de realizar o hacer efectivo un derecho es siempre positiva, costosa y de realización progresiva, y tiene como características principales facilitar, promover y asegurar el derecho definido.

Los Estados Miembros de las Naciones Unidas tienen responsabilidades respecto de los derechos humanos mediante tres vías (PNUD, 2000):

a) Aceptación: al ratificar o adherir un tratado se comprometen a permitir el examen internacional de su historial en materia de derechos humanos;

b) Cooperación: al ratificar un tratado, tienen la obligación de presentar un informe inicial sobre la materia del mismo en un plazo de uno o dos años, e informes periódicos subsiguientes; los que no han ratificado algún tratado tienen que colaborar con solicitudes de relatores especiales y otros procedimientos similares, invitándolos a visitar el país;

c) Respuesta: al hacerse parte de un tratado se comprometen a cooperar con el órgano creado en virtud de ese tratado, adoptando medidas en respuesta a sus observaciones y criterios finales.

Estas vías establecen mecanismos concretos para que los Estados comiencen a desarrollar acciones específicas desde el momento de la ratificación de un tratado. Sin embargo, no todos cumplen estas condiciones (PNUD, 2000), lo que hace evidente la necesidad de encontrar estrategias que permitan que los tratados y convenciones sean realmente respetados. No obstante, como afirma Peter Singer (2003), el derecho internacional está evolucionando hacia una comunidad global más fuerte. La soberanía de los Estados ya no reside en su poder para controlar lo que pasa al interior de sus fronteras: los límites de la soberanía radican en la capacidad y voluntad de los Estados de proteger a sus miembros, lo que justifica la intervención externa en aquellos Estados que no respetan los derechos humanos, en especial los que cometen crímenes de lesa humanidad. Las Naciones Unidas son la única entidad que puede intervenir legítimamente en estas situaciones. Para avanzar en una comunidad ética global -la construcción y respeto del paradigma de los derechos humanos-, es necesario que las naciones más poderosas acepten la autoridad de las Naciones Unidas, y le proporcionen los medios para cumplir con esa responsabilidad. Esta cuestión ha sido fuertemente enfatizada por su Secretario General ${ }^{11}$.

\section{Los instrumentos internacionales de derechos humanos}

La Carta de las Naciones Unidas (1945) es el primer instrumento internacional de derechos humanos. Sin embargo, la herramienta base es la Carta Internacional de Derechos Humanos, integrada por: la Declaración Universal de Derechos Humanos (1948), el Pacto Internacional de Derechos Económicos, Sociales y Culturales -ICCPR- (1966) y el Pacto Internacional de Derechos Civiles y Políticos

${ }^{13}$ Véase la intervención del Secretario General de las Naciones Unidas ante la Asamblea General en septiembre del 2004, donde llamó a reforzar el papel de las Naciones Unidas. Disponible en http://www.un.org/spanish/aboutun/organs/ga/59/webcast/statements/annan_dg59.html. 
-ICESCR- (1966), y sus dos Protocolos Facultativos. Estos documentos definen los derechos humanos y libertades fundamentales, estableciendo normas básicas que han inspirado la redacción de más de 50 convenciones, declaraciones, conjuntos de reglas y principios de derechos humanos de las Naciones Unidas (Naciones Unidas, 1991a). Entre ellos, los más importantes, por su carácter vinculante, son:

- Convención Internacional sobre la Eliminación de todas las Formas de Discriminación Racial -ICERD- (1965);

- Convención sobre la Eliminación de todas las Formas de Discriminación contra la Mujer (1979);

- Convención contra la Tortura y otros Tratos o Penas Crueles, Inhumanos o Degradantes -CAT- (1984);

- Convención sobre los Derechos del Niño (1989) -CDR-; y

- Convención Internacional sobre la Protección de los Derechos de todos los Trabajadores Migratorios y sus Familiares -MWC- (1990).

El cumplimiento de los tratados por parte de los Estados partes es supervisado por siete órganos de vigilancia, los "Comités", existiendo uno para cada tratado. Su trabajo es clave para fomentar el cumplimiento de los acuerdos suscritos por los países. A diferencia del Tribunal Europeo de Derechos Humanos y de la Comisión Europea de Derechos del Hombre, los comités no constituyen un tribunal o un órgano con un mandato casi judicial: sus decisiones corresponden a "opiniones" y no a "sentencias" (Naciones Unidas, 1991a). Evidentemente, esto debilita las posibilidades reales de sancionar a los Estados que no cumplen con los compromisos contraídos. Sin embargo, según las Naciones Unidas (1991a), la sanción y presión morales pueden tener gran influencia en la acción de los países y la adopción de medidas administrativas, judiciales y legislativas. Un ejemplo claro fue la apertura a la observación internacional que las dictaduras militares del Cono Sur se vieron obligadas a aceptar, lo que tuvo efectos de contención a los atropellos que hoy son ampliamente reconocidos.

Además de los comités, existen dos órganos creados en los primeros años de las Naciones Unidas. Primero, la Comisión de Derechos Humanos, cuyo mandato consiste en examinar y vigilar la situación de los derechos humanos en países o territorios específicos (mecanismos o mandatos por país) y fenómenos importantes de violaciones de los derechos humanos a nivel mundial (mecanismos o mandatos temáticos), e informar públicamente al respecto en ambos casos. La Sexagésima Cumbre Mundial de las Naciones Unidas, realizada en septiembre del 2005, decidió reemplazarla por un Consejo de Derechos Humanos.

El segundo es la Subcomisión para la Promoción y Protección de los Derechos Humanos, principal órgano subsidiario de la Comisión, integrado por expertos que realizan estudios específicos. Adicionalmente, en 1993 se creó el cargo de Alto Comisionado de los Derechos Humanos, que coordina los programas sobre esta temática al interior de las Naciones Unidas y se preocupa de fomentar su promoción y respeto en el mundo. 
Como menciono más adelante en este documento, todos los instrumentos establecen derechos humanos que se vinculan con los fenómenos de población. Además, las Naciones Unidas han realizado varias conferencias internacionales relevantes para los derechos humanos y los fenómenos de población, ya sea porque tratan específicamente el tema de derechos humanos o porque abordan temáticas específicas de población desde una perspectiva de derechos. Especial importancia tienen la Conferencia Internacional de Derechos Humanos de Teherán (1968), la Conferencia Internacional sobre la Población y el Desarrollo de El Cairo (1994), la Conferencia Mundial de Derechos Humanos de Viena (1993), la Conferencia de Beijing (1995), la Declaración del Milenio (2000) y el Plan de Acción Internacional de Madrid sobre el Envejecimiento (2002). Si bien estas conferencias no son vinculantes, los Estados han suscrito compromisos específicos en materia de población, desarrollo y derechos humanos, los cuales pueden ser exigibles. Un ejemplo claro es la acción de las organizaciones de mujeres destinada a respetar los acuerdos del Plan de la Acción de la CIPD y Beijing, en materia de derechos en salud y reproducción ${ }^{12}$.

\section{LAS INTERSECCIONES DE LA POBLACIÓN, EL DESARROLLO Y LOS DERECHOS HUMANOS}

Hablar de intersecciones de los fenómenos de población, el desarrollo y los derechos humanos supone puntos de encuentro entre la dinámica y el estado de la población, el desarrollo y los derechos humanos. Remite al intento de conciliar una perspectiva macro-social, la de las tendencias de las variables demográficas, el tamaño de la población y su distribución etaria, o los ritmos de crecimiento de la población y su relación con los recursos disponibles, con una perspectiva micro-social que pone énfasis en el individuo en su relación con el Estado. En la medida en que las tendencias demográficas son, en última instancia, resultado de comportamientos individuales que responden a una particular inserción social, histórica, económica, cultural y comunitaria, la intersección busca conciliar los intereses sociales referidos a la dinámica y estado de la población, con los intereses individuales referidos a los aspectos que inciden en esta dinámica y estado. Conciliar los intereses sociales e individuales referidos a la dinámica y el estado de la población no es una tarea fácil. Alude a cuestiones cruciales de la vida de todas las personas: dónde vivir y cuándo trasladarse de un lugar a otro; tener hijos o no tenerlos; cuántos hijos tener y en qué momento; cuándo y cómo morir. Este último aspecto cada vez cobra más importancia, dados el avance científico y las posibilidades de mantener la vida de una persona por medios artificiales, lo que pone en el tapete el problema del encarnizamiento terapéutico y la necesidad de establecer límites humanos al progreso científico. En otras palabras, la necesidad

12 Véase, por ejemplo, ATENEA, "El monitoreo como práctica ciudadana de las mujeres", de la Red de Salud de las Mujeres Latinoamericanas y del Caribe (RSMLAC), destinado a monitorear los acuerdos de la CIPD http://www.ateneareddesalud.org/ 
de dar respuestas a dilemas instalados por la tecnociencia pero que no pueden ser resueltos por ella, lo que dió pie al inicio de la bioética a fines de los años sesenta.

Estas situaciones trascendentales para la vida de cada persona se enfrentan con cuestiones y preguntas trascendentales para los Estados: la relación poblaciónrecursos, o cómo satisfacer las demandas de una población que crece sostenidamente y, en algunos países en desarrollo, a ritmos mucho más elevados de lo que sus gobiernos desearían. En el otro polo, algunos países desarrollados, principalmente europeos, crecen a ritmos tan bajos que su propia sobrevivencia estaría amenazada de no contar con la inmigración internacional. Ni las esterilizaciones forzadas, ni el retiro de todo método de anticoncepción, representan alternativas para solucionar tales situaciones: ambas implican la violación de varios derechos humanos.

¿Qué factores inciden en las intersecciones de población, desarrollo y derechos humanos? ¿Bajo qué condiciones se profundizan o complejizan tales intersecciones? Sin duda, el progreso científico y tecnológico, especialmente en el campo biomédico, es un aspecto central. Basta recordar el rol jugado por los avances sanitarios en la transición demográfica y su simultaneidad con la transición epidemiológica, que le otorga sentido a la vinculación población, desarrollo y derecho a la salud. También, que el derecho a decidir el número y espaciamiento de los hijos fue reconocido por primera vez en 1968, pocos años después de la aparición y comercialización de la píldora anticonceptiva. Más de 40 años después, el desarrollo de las técnicas de reproducción asistida agrega una nueva dimensión a los derechos reproductivos, como es el derecho a reproducirse utilizando tales técnicas, especialmente cuando esa práctica se va instalando como recurso efectivo para mujeres o parejas con problemas de fertilidad. El panorama es complejo, porque paralelo al desarrollo de la tecnociencia actúan factores religiosos, culturales y económicos, los que inciden en este desarrollo y en las elecciones de las personas, pudiendo llegar a limitar su propia capacidad de elección, es decir, su autonomía.

No sólo los avances tecnocientíficos en el campo biomédico son centrales en las intersecciones de población, desarrollo y derechos humanos. Los avances en el transporte y las comunicaciones internacionales, que han tenido un aumento sin precedentes, han incidido con fuerza en el crecimiento sostenido de la migración internacional. Cientos de miles de personas, provenientes en su mayoría de países en desarrollo, viven en países desarrollados, muchos de ellos en condiciones de extrema vulnerabilidad, o son derechamente vulnerados. También se han intensificado las migraciones entre países en desarrollo, siendo los de mayor desarrollo relativo los que tienden a atraer una mayor cantidad de migrantes. Tal es el caso, por ejemplo, de Costa Rica en Centroamérica. El tema es complejo, porque pone en la agenda pública cuestiones diversas e incluso contradictorias: la integración social y cultural; el respeto a la diversidad cultural y la diferencia; las necesidades económicas, de empleo y de seguridad social. Se trata, a fin de cuentas, 
de encontrar la manera de conciliar los intereses sociales tendientes al bienestar del grupo, con los intereses individuales orientados a la autodeterminación de los individuos en tanto seres autónomos. En otras palabras, de conciliar principios macro-éticos y micro-éticos, dilema permanente de los tomadores y tomadoras de decisiones de política pública. Los intereses globales o nacionales afectan, en última instancia, a las personas y sus proyectos individuales y familiares de vida, lo que remite a las intersecciones de los fenómenos de población, el desarrollo y los derechos humanos.

La tarea de conciliar los intereses sociales respecto de la dinámica demográfica, con los intereses individuales que se relacionan con esta dinámica, alude a tareas cruciales que el Estado debe asumir. Por ejemplo, cómo conciliar el tamaño, distribución y crecimiento de la población con los recursos y medios disponibles para atender las demandas de esa misma población sobre un conjunto de servicios, principalmente sanitarios, de empleo, educación, previsión social y vivienda, pero también en relación con la infraestructura urbana o el poblamiento de zonas de interés estratégico. El asunto es más complejo aún si se considera el fenómeno de la pobreza, debido a las conocidas interrelaciones de una dinámica demográfica tendiente a mayor fecundidad y mayor mortalidad materna e infantil, y la reproducción de la pobreza. El interés que manifiestan todos los gobiernos en reducir la pobreza, expresado con fuerza en la Declaración del Milenio, debiera plasmarse en políticas que incidan en la dinámica demográfica, pero que a la vez respeten los derechos de los seres humanos que viven en esa situación.

\section{Población, desarrollo, derechos humanos ¿Estamos hablando de un asunto nuevo?}

Las propuestas para aplicar un enfoque de derechos humanos a los fenómenos de población y desarrollo no son asuntos nuevos, aunque los ejes de las discusiones se han modificado y se han agregado nuevos temas. En el campo de los derechos humanos se observó por primera vez a fines de los años sesenta en la Conferencia de Teherán. El énfasis se centró en el derecho a la planificación de la familia o, en la terminología actual, en los derechos reproductivos. Tales derechos son parte de la legislación internacional sobre derechos humanos, reconocidos especialmente por la CEDAw. Dado que los derechos son indivisibles, interdependientes y están relacionados entre sí (Conferencia de Derechos Humanos de Viena de 1993), estos derechos se relacionan directamente con otros, tales como el de la salud (artículo 12 del ICESCR), e indirectamente con el de la libertad de buscar, recibir y difundir información de toda índole (artículo 19 del ICCPR) y con el de la libertad de conciencia, creencia y religión (artículo 18 del ICPR).

Las intersecciones no sólo han sido tratadas desde los derechos humanos, sino también desde el campo de la población. Es sabido que las posturas que defendían la planificación familiar durante los años sesenta y setenta fueron ampliamente criticadas por su desconocimiento y omisión de las relaciones población-desarrollo, crítica muy bien resumida en la frase "el desarrollo es el mejor anticoncep- 
tivo". Sin embargo, las críticas apuntaron también, aunque con menor fuerza, a la violación de los derechos humanos. Evidencia de esto es la Conferencia Mundial de Población de Bucarest (1974), que estableció que la planificación de la familia es un derecho fundamental de todas las parejas e individuos. La consagración definitiva de la inclusión de la perspectiva de derechos humanos se produjo sin dudas en la CIPD, que además de referirse a los fenómenos de población desde la perspectiva de sujetos de derecho, legitimó el concepto de derechos reproductivos y aplicó el enfoque de derechos humanos a los distintos de la población y el desarrollo.

Las actividades de las Naciones Unidas en el campo de la población y los derechos humanos se iniciaron en 1974, cuando se realizó en Amsterdam la Primera Reunión del Grupo de Expertos de las Naciones Unidas sobre Población y Derechos Humanos. Una segunda reunión tuvo lugar en Viena (1981) y una tercera en Ginebra (1989). El propósito de esta última fue evaluar la situación en ese momento respecto de las relaciones de la fecundidad, la mortalidad y el crecimiento de la población y los asuntos de derechos humanos, y proponer acciones al respecto (United Nations, 1990). Es importante revisar los temas abordados en ese último encuentro, pues marcan la pauta de las preocupaciones presentes hasta ese momento: anticoncepción y planificación familiar; aborto; incentivos y desincentivos en políticas de fecundidad; nuevas biotecnologías, políticas de población y derechos humanos; atención de salud y derechos humanos, incluyendo el SIDA; derechos humanos, enfermedades terminales y eutanasia; y derechos humanos, envejecimiento de la población y equidad intergeneracional.

Como se observa, las temáticas fueron diversas. Muchas de ellas tienen mayor importancia que hace 15 años, en particular las referidas a las nuevas biotecnologías, enfermedades terminales y eutanasia y envejecimiento de la población, y equidad intergeneracional. Incluso, han llegado a ser significativas para algunos países en desarrollo, entre ellos muchos latinoamericanos, dado el avance de sus transiciones demográficas y epidemiológicas. Para otros países en desarrollo, en cambio, no son aún importantes, pero sin duda lo serán en un futuro no lejano. La reunión entregó un conjunto de sugerencias que pueden ser plenamente consideradas en la actualidad. Entre ellas, se afirmó que los derechos humanos no pueden ser tomados como estructuras rígidas, ya que no son los mismos en todos los tiempos ni en todos los lugares, y reflejan el consenso internacional alcanzado en un determinado momento. Por ello, el desarrollo de derechos humanos relevantes para los fenómenos de población puede incluir la reformulación de los existentes o la formulación de derechos humanos nuevos. Se sugirió también que existía una importante necesidad de revisar los derechos relacionados con población que habían sido aceptados por la comunidad internacional, y que estaban diseminados en una diversidad de instrumentos internacionales. Complementariamente, se advirtió sobre la necesidad de evaluar la observancia e implementación de los derechos humanos existentes. Por último, la reunión recomendó: a) poner atención a las consecuencias sociales, económicas y legales, incluyendo riesgos 
y beneficios, de la reproducción médicamente asistida, el diagnóstico prenatal, la manipulación genética y la investigación en embriones; b) implementar normas éticas y jurídicas orientadas a asegurar el consentimiento libre e informado en materias referidas a cualquier intervención externa sobre el proceso reproductivo; c) considerar las implicancias de los derechos humanos vinculados con el envejecimiento de la población; y d) difundir información actualizada, confiable y pertinente para que las personas y las parejas hagan pleno ejercicio de sus derechos humanos referidos a población, lo que remite a las actividades de advocacy o promoción de la causa.

Si bien algunos de estos temas pueden parecer irrelevantes para los países en desarrollo, existen al menos tres razones para considerarlos seriamente. Primero, muchos países en desarrollo han realizado importantes avances en el campo científico y tecnológico, como Brasil y $\mathrm{Cuba}^{13}$ en el caso regional. Segundo, el fenómeno del envejecimiento ya es un hecho en varios países latinoamericanos y caribeños. De hecho, según las proyecciones vigentes, en todos los países latinoamericanos, y en gran parte de los caribeños, la tasa de crecimiento de la población de 60 años y más es mayor que la tasa de crecimiento total, y en más de la mitad de ellos este grupo etario representa el 7\% o más del total de su población. Tercero, otros temas emergentes, derivados de los fenómenos anteriores, están cobrando importancia mundial. Por ejemplo, la clonación terapéutica y reproductiva; la genómica y las posibilidades de diagnóstico temprano y manipulación genética; los matrimonios entre homosexuales y la discusión sobre su derecho a la adopción. La unión civil entre homosexuales ya es permitida en la Ciudad Autónoma de Buenos Aires. En otros países, como es el caso de Chile, se discute la posibilidad de legislar sobre las uniones homosexuales, con el objetivo de solucionar problemas asociados a la propiedad común y la herencia. Las discusiones sobre la adopción parecieran ser más lejanas, pero el desarrollo de las técnicas de reproducción asistida y la posibilidad de "alquilar" vientres, pueden modificar la situación sin necesidad de legislar al respecto. Estos nuevos arreglos familiares y reproductivos tendrán impactos hasta ahora imprevisibles sobre la dinámica demográfica, en especial sobre la fecundidad. De la misma manera, pueden repercutir en la forma cómo se conceptualiza y mide la fecundidad (por ejemplo, ampliación del período reproductivo, cambio del sujeto y la base de las medidas resúmenes) y por ello, en una redefinición de los sujetos y contenidos de las políticas públicas en el área. La rapidez del avance científico exige que estos temas sean incorporados a la discusión y reflexión públicas, de manera tal de posibilitar el respeto a la autonomía de las personas y la existencia de espacios para la expresión de la diversidad, asuntos todos vinculados a las intersecciones de población, desarrollo y derechos humanos.

15 Véase M. Ferrer y otros (2004), “The scientific muscle of Brazil's health biotechnology”, Nature Biotechnology, Volume 22, Supplement December (pp. 8-12) y H. Thorsteinsdóttir y otros (2004), "Cuba - innovation through synergy", Nature Biotechnology, Volume 22, Supplement December (pp. 19-24), disponibles en http://www.utoronto.ca/jcb/home/news_nature.htm. 


\section{¿CUÁLES DERECHOS HAN SIDO RECONOCIDOS?}

Identificar los derechos humanos vinculados con fenómenos de población y desarrollo pareciera ser, a primera vista, un trabajo sencillo. Se trataría de revisar los tratados, convenciones o conferencias y seleccionar aquellos derechos que se relacionan con la fecundidad, la mortalidad y la migración. Sin embargo, la tarea no consiste simplemente en seleccionar los derechos asociados con estos fenómenos, sino aquellos derechos que habilitan a los seres humanos para actuar y definir libremente sus propios proyectos de vida, respecto de materias relacionadas con estas tres variables del cambio demográfico, o aquellos derechos que contribuyen a este fin.

Por ejemplo, el derecho de las mujeres al trabajo en igualdad de condiciones que los hombres (artículo 11 de la CEDAw) se relaciona con la fecundidad, pues es sabido que la incorporación de las mujeres al trabajo es un factor de su descenso. Sin embargo, su relación con la fecundidad no es directa, sino que opera por la vía del ofrecimiento de otras expectativas de vida, el mejoramiento de las condiciones económicas, la superación de la pobreza, entre otros, que en conjunto actúan sobre las variables intermedias de la fecundidad. Por contraste, el derecho de las mujeres a recibir servicios de planificación de la familia (artículo 12 de la CEDAw), las habilita para actuar libre e informadamente sobre su propia fecundidad, ya sea para mantener el número promedio de hijos de su sociedad, aumentarlo o disminuirlo. La diferencia entre ambos derechos es clara: el último incide directamente sobre las decisiones de fecundidad que toman las mujeres -o las parejas-, en tanto el primero lo hace indirectamente. Es un hecho que las interrelaciones entre población y desarrollo son amplias e incluyen un conjunto numeroso de factores. La pregunta que surge entonces es: ¿hasta dónde incluir aquellos derechos que inciden indirectamente?

El trabajo del Alto Comisionado de las Naciones Unidas para los Derechos Humanos, referido a la aplicación de un enfoque de derechos humanos a las estrategias de reducción de la pobreza, entrega ciertas orientaciones al respecto, distinguiendo entre derechos con pertinencia constitutiva e instrumental para el contenido y las estrategias de reducción de la pobreza ${ }^{14}$. Utilizar el criterio de pertinencia constitutiva y pertinencia instrumental orienta la identificación de aquellos derechos que habilitan a los seres humanos para actuar y tomar decisiones libres e informadas sobre su fecundidad, mortalidad y migración (pertinencia constitutiva) o aquellos derechos humanos que contribuyen a actuar o tomar decisiones libres e informadas sobre aspectos relacionados con su fecundidad, mortalidad y migración o cuya ausencia incide negativamente en esto (pertinencia instrumental). Por ejemplo, el derecho a elegir libremente el lugar de residencia tiene pertinencia constitutiva respecto de la migración, mientras que el derecho al trabajo tiene pertinencia instrumental, en el sentido de evitar la migración forzada por razones laborales.

${ }^{16}$ Véase OACDH, 2004. 
Una estrategia para exigir el respeto de los derechos humanos vinculados a los fenómenos de población y desarrollo debiera incluir ambos tipos de derechos, especificando sus diferencias, alcances y relevancias. Si bien esta perspectiva es útil para diferenciar los derechos a incluir, no permite responder la pregunta sobre los límites o hasta dónde incluir los derechos con pertinencia instrumental a los fenómenos de población. Esto requiere el logro de consensos respecto de cuáles derechos son más importantes que otros para estos efectos ${ }^{15}$, lo que en última instancia traslada la discusión al terreno ético. Considerando estos aspectos, en los siguientes cuadros presento los derechos humanos con pertinencia constitutiva e instrumental para las variables de población, que son reconocidos en los instrumentos vinculantes de la legislación internacional sobre derechos humanos: ICCPR, ICESCR, ICERD, CEDAW, CAT, y CRC. Por su carácter fundador, y según algunos de ley internacional consuetudinaria (Gostin, 2001) incluyo también la Declaración Universal de los Derechos Humanos (DUDH). No incluyo la MWC, pues es en sí mismo un instrumento sobre un fenómeno de población. (cuadro 1a y 1b)

Como se observa, los derechos con pertinencia constitutiva para la fecundidad se refieren a situaciones que habilitan para decidir sobre tener hijos o no, y acceder a servicios de salud, consejería e información. El derecho base es decidir el número y espaciamiento de los hijos, y el de contar con servicios e información para ejercer este derecho.

Los derechos con pertinencia instrumental aluden a un conjunto de condiciones que permiten a las mujeres y/o parejas estar en una mejor situación para ejercer su derecho a decidir libremente el número y espaciamiento de sus hijos (educación, trabajo y seguridad social). Incluye también el derecho de toda persona a la vida, que fundamenta la aceptación del aborto inducido en los casos en que peligra la vida de la mujer, respetando su autonomía en la decisión. Por último, se incluyen dos garantías que deben ser respetadas en cualquier estrategia orientada a hacer efectivo el derecho a la autodeterminación reproductiva: el de la libertad de pensamiento, conciencia y religión, y el derecho a la libertad de expresión, incluyendo la búsqueda de información. Ambos se ven violados cuando, a solicitud de ciertos grupos religiosos o fundamentalistas, el gobierno limita o restringe los contenidos de servicios en salud sexual o reproductiva, en función de cuestiones religiosas o valóricas.

Por último, es importante mencionar que sólo indirectamente se alude al tema de la reproducción asistida, por la vía del derecho a gozar de los avances del progreso científico y sus aplicaciones. Dados los avances en esta materia, varios países han incluido las técnicas de reproducción asistida dentro de sus programas de salud pública, lo que abre la discusión sobre el derecho al acceso a estos procedimientos, y sobre las temáticas asociadas al diagnóstico prenatal.(cuadro 2)

${ }^{15}$ Dado que los derechos humanos son indivisibles, interdependientes y están relacionados entre sí, no cabe realizar una jerarquía de derechos. El sentido de la jerarquía que propongo acá se da en relación con la selección de los derechos vinculados con los fenómenos de población y desarrollo. 


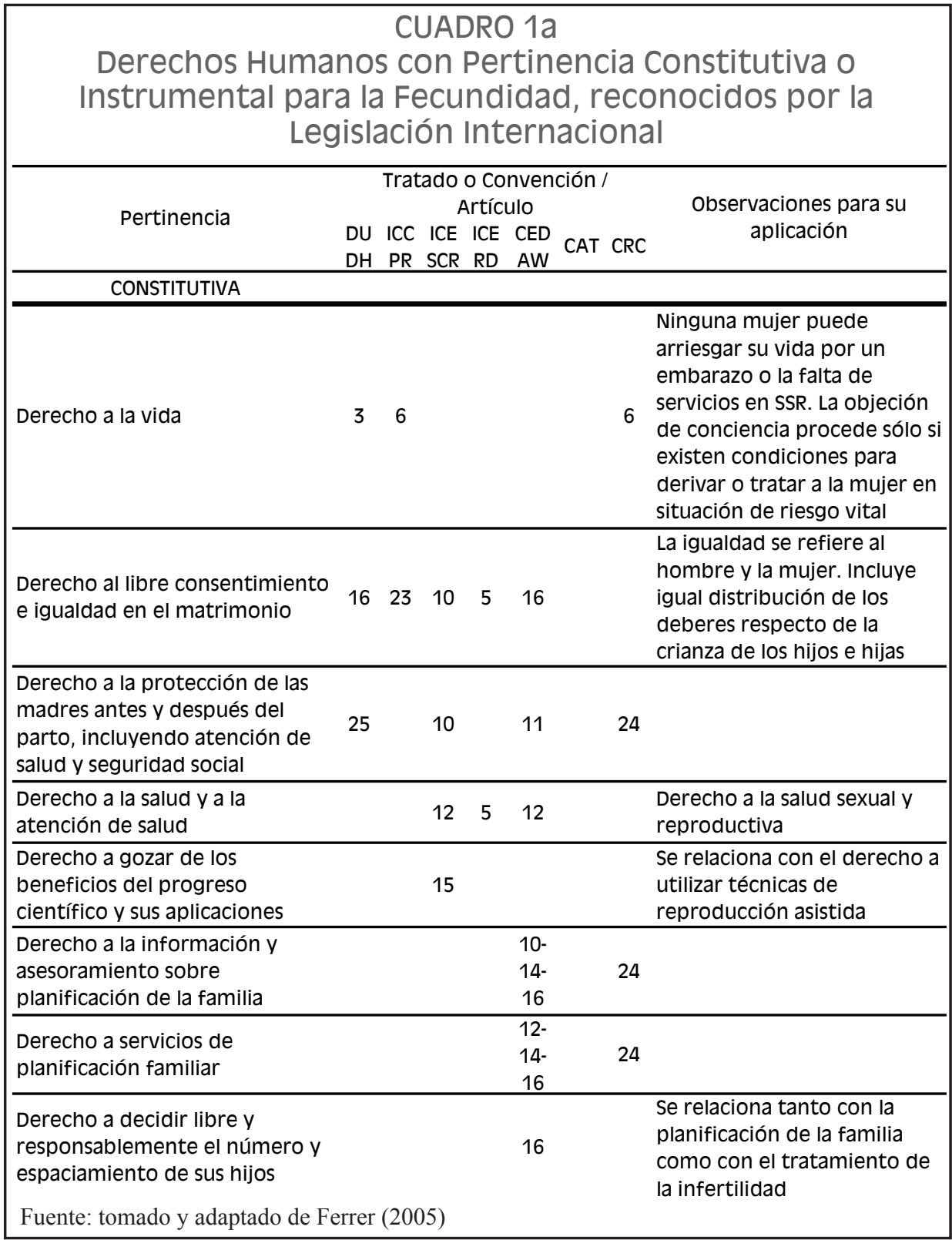

Los derechos con pertinencia constitutiva para la mortalidad se refieren a un conjunto de condiciones que permiten mantener la vida y retrasar el momento de la muerte. El derecho base es el referido a la salud, que es entendido tanto en relación con los servicios de atención de salud como con los macrodeterminantes de las condiciones de la salud.

Los derechos con pertinencia instrumental remiten a un conjunto de condiciones que permiten a los seres humanos estar en mejores condiciones materiales y psicológicas para preservar la vida y retrasar la muerte, como son el derecho a la educación, al trabajo y a la seguridad social. 


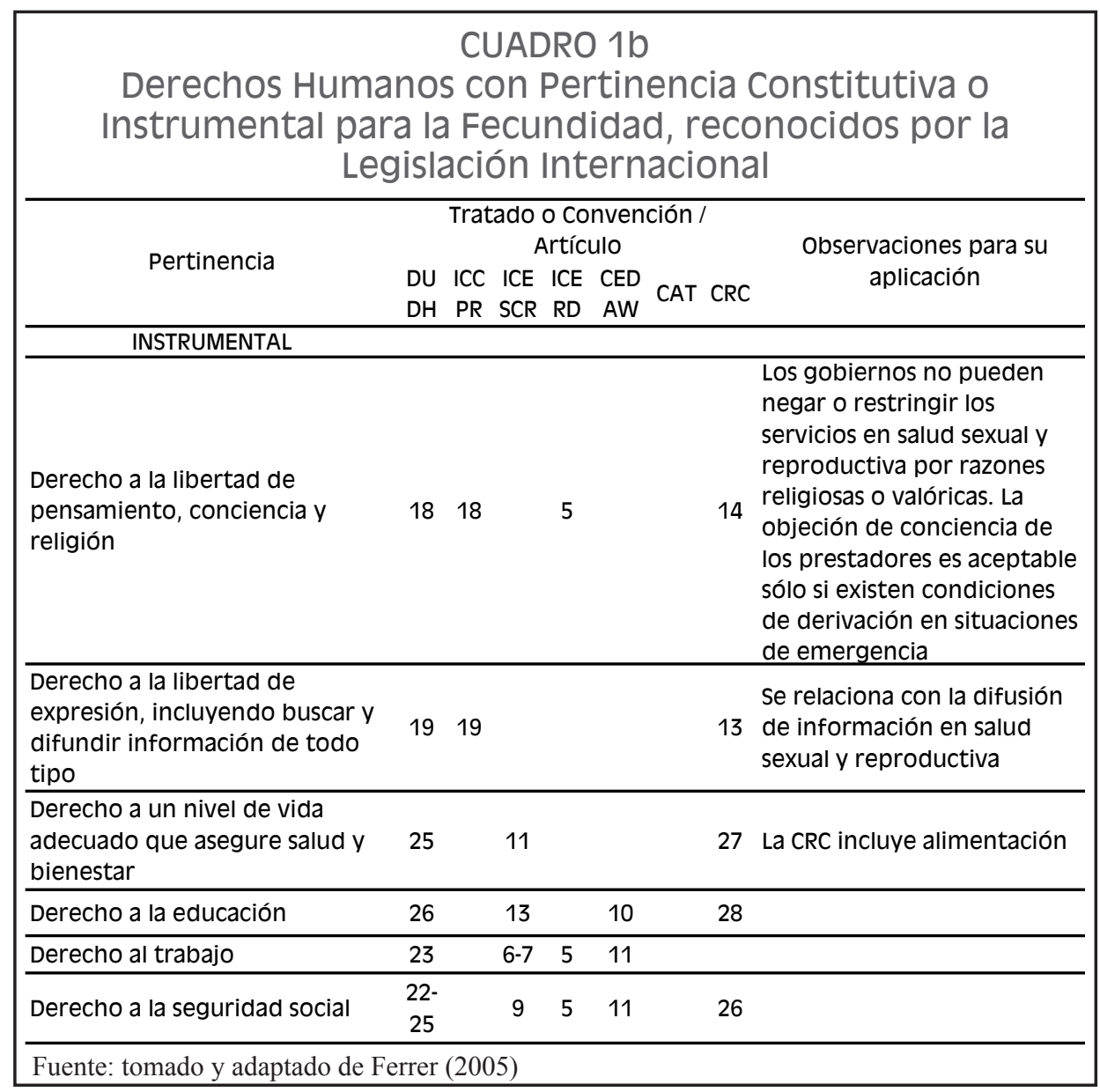

Por último, es importante consignar que la legislación internacional sobre derechos humanos no ha abordado los fenómenos de prolongación artificial de la vida humana o del "encarnizamiento terapéutico", derivados de los avances de la tecnociencia aplicados al campo de la medicina. No obstante, se ha reconocido el derecho a la autonomía y la integridad corporal, lo que implica el derecho a rechazar tratamientos o intervenciones médicas. Aquí se enmarca la discusión sobre la eutanasia y lo que algunos llaman el "derecho al buen morir", cuestión que cobra cada día más importancia y que debe ser planteada desde una perspectiva de derechos humanos. Se trata de un fenómeno que ha ganado protagonismo por efecto del envejecimiento de la población, aunque no es privativo de las edades avanzadas. Es también relevante en los recién nacidos con daño neurológico severo o en los casos de caer en un estado vegetativo permanente, cuyo riesgo está presente a cualquier edad. (cuadro 3) Existe sólo un derecho con pertinencia constitutiva para la migración interna: la libertad para decidir el lugar de residencia dentro del propio país. Por su parte, los derechos con pertinencia instrumental se refieren a un conjunto de condiciones que contribuyen a evitar la migración interna e internacional forzada, como son el de la educación, el trabajo y la se- 


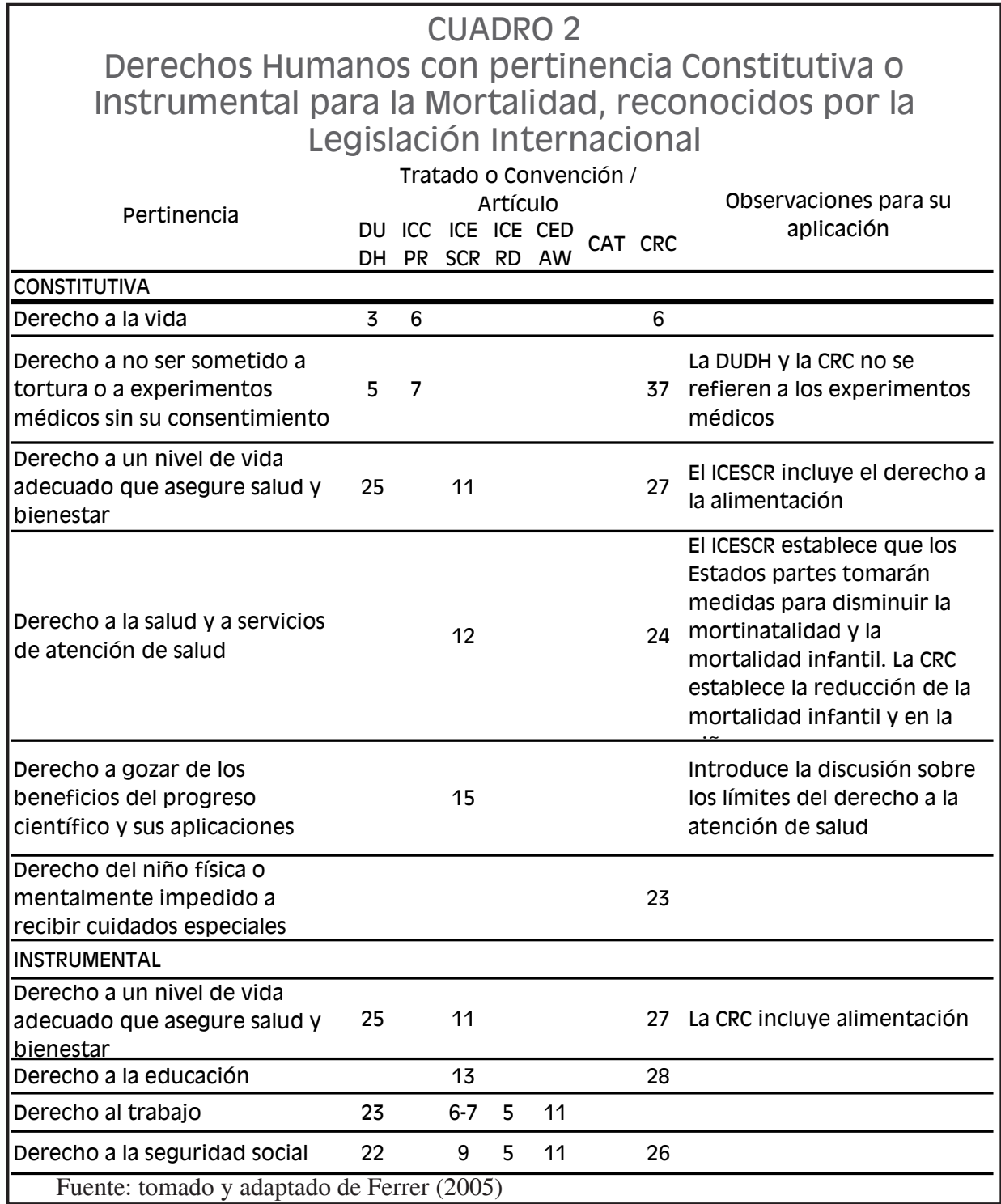

guridad social, y un nivel de vida adecuado que asegure la salud y el bienestar. Los restantes derechos con pertinencia instrumental aluden especialmente a la migración internacional. Se refieren a asegurar la igualdad y no discriminación con base en el origen nacional, étnico o religioso. Varios de estos derechos fueron recogidos en la Convención para la Protección de los Derechos de todos los Trabajadores Migratorios y sus Familiares (MWC). En síntesis, la legislación internacional sobre derechos humanos reconoce un conjunto de garantías que tienen pertinencia constitutiva o instrumental para las decisiones individuales relacionadas con las variables de población. Tales derechos han sido reconocidos también en las Conferencias Internacionales de Población y las Conferencias Internacionales de Derechos Humanos, en la Conferencia de Beijing y, más recientemente, en la Cumbre del Milenio, lo que les otorga mayor fuerza y abre un punto de partida 


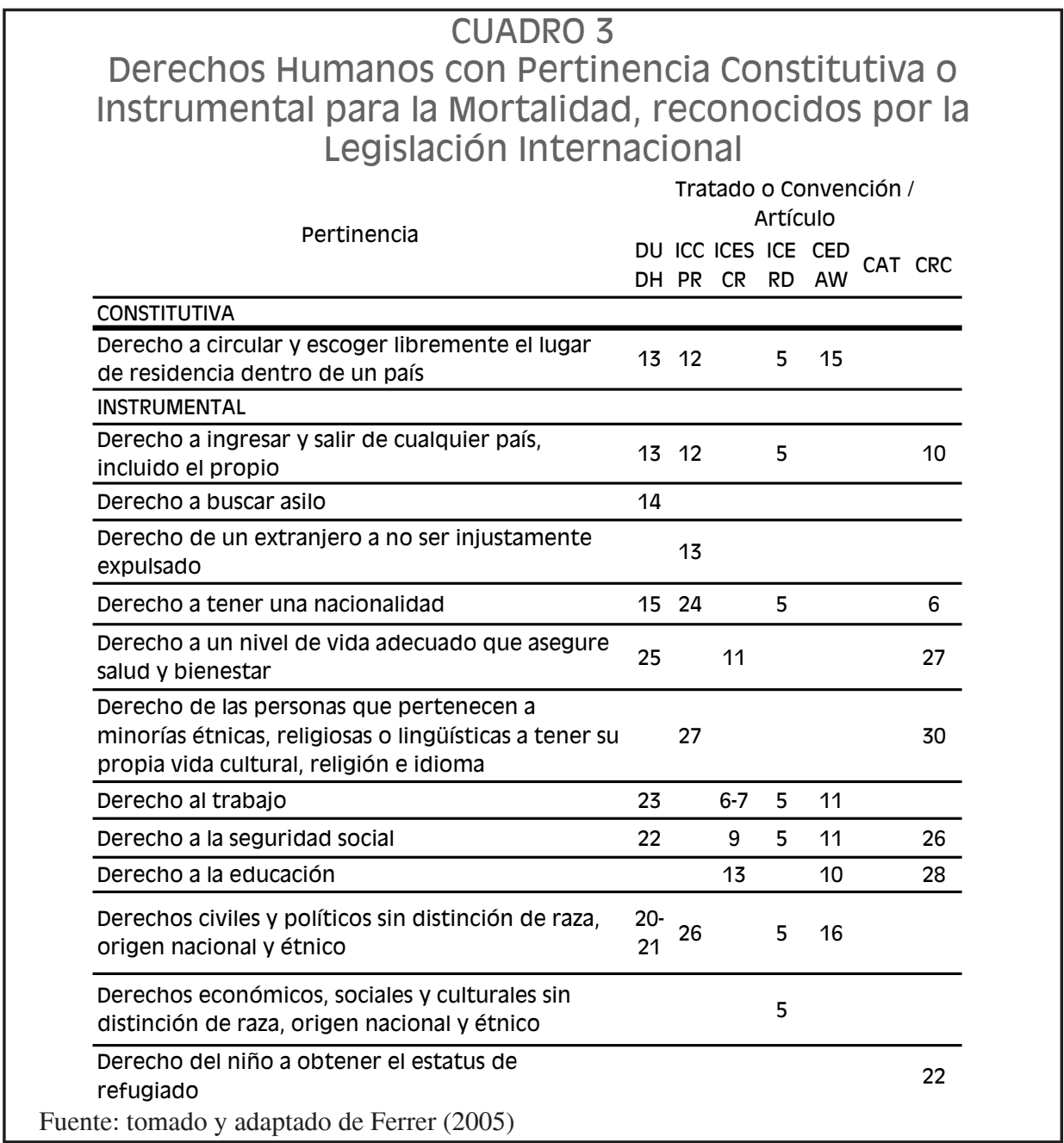

necesario para la profundización y la exigencia del respeto, reconocimiento, promoción y garantía de estos derechos humanos. Por último, es crucial enfatizar que todas las acciones tendientes a lograr una mayor equidad de género y un mejoramiento de las condiciones de vida de las mujeres, son centrales para producir avances en materia de derechos humanos en población y desarrollo. El principio de igualdad y no discriminación en razón de la raza, color, sexo, idioma, religión, opinión política o de cualquier otra índole, origen nacional o social, posición económica, nacimiento o cualquier otra condición es transversal a todos los instrumentos de derechos humanos, lo que implica observar estos derechos desde la perspectiva de la desigualdad, y lo conecta directamente con las temáticas de la vulnerabilidad sociodemográfica. En esto no se incluye la discriminación por edad, que ha adquirido relevancia social debido al proceso de envejecimiento de la población y, por ello, fue incluido sólo recién en la Mwc. No obstante, los derechos humanos de los adultos mayores han sido reconocidos en el Plan de Acción Internacional de Madrid sobre el Envejecimiento. 


\section{OPORTUNIDADES Y DESAFÍOS DE LA APLICACIÓN DEL ENFOQUE DE} DERECHOS HUMANOS A LOS FENÓMENOS DE POBLACIÓN

Como ya mencioné, la aplicación de un enfoque de derechos humanos a los fenómenos de población no es un tema nuevo, ni para quienes han trabajado en derechos humanos, ni para quienes lo han hecho en el campo de la población. Sin embargo, se debe reconocer que sus intersecciones no han sido reconocidas ni trabajadas con profundidad. Emprender esta línea de trabajo tiene múltiples derivaciones relevantes para los países de la región. En especial, orientar los procesos de formulación, implementación y evaluación de las políticas públicas en población y desarrollo desde un enfoque de derechos humanos, como también ampliar las fronteras de la investigación y reflexión en el campo de la población. Sin duda, el desarrollo de esta línea lleva implícito el riesgo de las controversias propias de la introducción de nuevas miradas en temáticas consolidadas. Sin embargo, es necesario asumir este desafío y sus riesgos, pues los países de la región siguen enfrentando demandas de protección de los derechos humanos en un contexto de desigualdad creciente, a la par que los avances de la tecnociencia en el campo biomédico, el transporte y las comunicaciones siguen introduciendo nuevos dilemas éticos de absoluta relevancia en el campo de la población y el desarrollo.

A continuación resumo varios de los planteamientos formulados en este trabajo, junto con el planteamiento de las oportunidades y desafíos que presenta el desarrollo de esta área de trabajo, tanto en relación con la aproximación global al tema, como con el desarrollo de líneas de investigación.

\section{Sobre la aproximación global al tema}

1. Referirse a las intersecciones de los fenómenos de población, desarrollo y derechos humanos implica suponer puntos de encuentro entre la dinámica y el estado de la población, el desarrollo y los derechos humanos. Se trata de conciliar una perspectiva macro-social, la de las tendencias de las variables demográficas, o los ritmos de crecimiento de la población y su relación con los recursos disponibles, con una perspectiva micro-social que pone énfasis en el individuo en su relación con el Estado. La intersección busca conciliar los intereses sociales referidos a la dinámica y estado de la población, con los intereses individuales referidos a los aspectos que inciden en esta dinámica y estado, entendiendo que las tendencias demográficas son, en última instancia, resultado de comportamientos individuales que responden a la particular inserción social, histórica, económica, cultural y comunitaria de esos individuos, y de los individuos con los cuales interactúa.

2. Las intersecciones de los fenómenos de población y los derechos humanos aluden a cuestiones cruciales de la vida de todas las personas: dónde vivir y cuándo trasladarse de un lugar a otro; tener hijos o no tenerlos; cuántos hijos tener y en qué momento; retrasar la muerte y, cuando es posible decidir, cuándo y cómo morir. Los avances científicos y tecnológicos relacionados con estos eventos, es- 
pecialmente en el campo biomédico, generan nuevos dilemas éticos que pueden estimular la redefinición o creación de nuevos derechos humanos. Sin embargo, se debe tener en cuenta que la multiplicación de los derechos humanos lleva implícito el riesgo de hacerles perder su especificidad y fuerza. Por eso, es más conveniente maximizar los esfuerzos para que los actuales instrumentos de derechos humanos sean respetados, lo que puede incluir una relectura del contenido o ámbito de aplicación de los derechos que ya han sido reconocidos, y que se vinculan con los fenómenos de población y desarrollo.

3. Para que el enfoque de derechos humanos en temas de población y desarrollo sea efectivo y pueda tener injerencia en políticas públicas, es necesario remitirse a la legislación e instrumentos internacionales de derechos humanos. Los derechos humanos son fruto de acuerdos o pactos sociales, que buscan definir ciertos estándares de justicia en las condiciones de vida de los seres humanos y en su relación con el Estado, ya sea directamente o en su rol de mediador (por ejemplo, de la relación empresario-trabajadores por la vía de los derechos laborales y sindicales), bajo el principio de igualdad y no-discriminación. En tanto acuerdos sociales, están sujetos a revisión y modificación. Sin embargo, esto supone lograr altos niveles de consenso entre los países, por lo que el trabajo en población $\mathrm{y}$ derechos humanos debe tener un componente importante de actividades de advocacy o promoción de la causa, de fortalecimiento de la participación de la ciudadanía (cuestión que en sí misma es un asunto de derechos humanos), y el desarrollo de conferencias u otras instancias internacionales que permitan lograr consensos sobre el tema.

4. Un punto de partida para identificar derechos humanos vinculados con fenómenos de población es utilizar la distinción entre pertinencia constitutiva y pertinencia instrumental. Los primeros corresponden a aquellos que habilitan a los seres humanos para actuar y tomar decisiones libres e informadas sobre su fecundidad, mortalidad y migración. Los segundos aluden a aquellos que contribuyen a actuar o tomar decisiones libres e informadas sobre aspectos relacionados con esos mismos fenómenos, o cuya violación afecta negativamente la libertad para tomar tales decisiones. Existen varios derechos humanos consagrados en la legislación internacional que cubren estas dimensiones, los que han sido además reconocidos en diversas conferencias internacionales. No obstante, el límite teórico de los derechos con pertinencia instrumental corresponde a todos los derechos humanos, dada su indivisibilidad, interdependencia e interrelación. Por ello, parece más conveniente profundizar en aquellos que tienen pertinencia constitutiva para las variables del cambio demográfico, abogar por su respeto, protección y garantía, especificando el sentido y ámbito que tienen para cada una de estas variables, las interrelaciones entre éstas, y de éstas con los procesos de desarrollo.

5. En el plano de las políticas públicas, la aplicación del enfoque de derechos humanos tiene un doble efecto. Por un lado, permite exigir que los Estados tomen medidas o formulen políticas, a lo que están obligados por los convenios o pactos de los cuales son parte. Ejemplo máximo es la obligación de tomar medidas con- 
tra la pobreza, porque implica la violación de varios derechos humanos. Por otro lado, constituye una guía para definir su contenido. Por ejemplo, las políticas para disminuir la pobreza deben considerar la entrega de información y la generación de espacios de participación para los pobres, puesto que ambos constituyen derechos reconocidos en el Pacto de Derechos Civiles y Políticos; y deben además propender a la igualdad de género y a la no-discriminación por otros criterios, ya que estos derechos también están reconocidos. Este doble efecto debe ser incorporado también en las políticas públicas referidas a la población y el desarrollo.

6. La aplicación del enfoque de derechos humanos a las políticas públicas implica un cambio en la visión y relación con las personas a quienes éstas se dirigen: ya no son "beneficiarios" sino "sujetos de derecho", por lo que, por ejemplo, no se atiende a la pobreza por caridad o valores morales, sino porque el Estado tiene la obligación de hacerlo. En otras palabras, las personas o grupos que se convierten en "beneficiarios" de esta política lo hacen en función de sus derechos y no de sus necesidades. El paternalismo debiera tender a desaparecer, puesto que el enfoque de derechos humanos implica considerar los derechos civiles y políticos, que propenden a la participación de los seres humanos en la vida social y en las decisiones públicas, como también a potenciar la autonomía de las personas respecto de distintos ámbitos de su vida social, privada y familiar.

7. Adoptar el enfoque de los derechos humanos implica necesariamente reforzar el papel del Estado, lo que se opone a los postulados neoliberales que plantean disminuir su acción, requisito que encabeza la lista de los procesos de reforma y modernización del Estado incentivados por los organismos financieros internacionales.

8. Para el trabajo en las intersecciones de los fenómenos de población y derechos humanos, es posible distinguir tres niveles de análisis. Primero, las variables de la dinámica demográfica (fecundidad, mortalidad y migración). Segundo, ciertas temáticas relevantes que resultan del comportamiento de esta dinámica, por ejemplo, los temas de salud sexual, salud reproductiva, mortalidad infantil y en la niñez o envejecimiento. Tercero, ciertos grupos que han adquirido relevancia por la dinámica demográfica, como son los adultos mayores ( $\mathrm{y}$, en su momento, los niños y los jóvenes), o por su vulnerabilidad sociodemográfica (como los pobres, la población indígena, las mujeres, los migrantes y sus respectivas combinaciones). Las fronteras entre estos tres niveles no son absolutas. Por ejemplo, el envejecimiento es un tema en sí mismo, pero también es necesario pensar en el principio de no discriminación por edad, es decir, atender a los adultos mayores como grupo y promover la observancia de los derechos humanos de las personas que pertenecen a ese grupo. En el mismo sentido, la salud sexual es un tema, pero también aplica a los adultos mayores, los indígenas y otros, en tanto derecho (hasta ahora no vinculante en la legislación internacional).

Una forma más clara de entender esto es que tanto los derechos que se relacionan -o se intersecan- con las variables de la dinámica demográfica, como con las temáticas de población y desarrollo, corresponden a derechos que se aplican a 
todos los seres humanos. En cambio, la consideración de los grupos que han cobrado importancia por la dinámica demográfica, o por su vulnerabilidad sociodemográfica, se realiza en función del combate contra la discriminación, que es la función de los derechos humanos. En realidad esto es muy similar al trabajo que se ha realizado con los instrumentos internacionales de derechos humanos. Primero, se definieron derechos para todos los seres humanos (Declaración Universal, Pacto de Derechos Civiles y Políticos, Pacto de Derechos Económicos, Sociales y Culturales). Luego, se identificaron derechos para ciertas temáticas que requerían atención especial (tortura y discriminación racial). Por último, se definieron derechos para individuos que pertenecen a grupos específicos, los que no quedaron suficientemente protegidos por los anteriores (mujeres, niños y migrantes). Evidentemente, esto tiene relación con la importancia política que adquieren ciertos temas y grupos, lo que refuerza la importancia de las actividades de advocacy y de fortalecimiento de la ciudadanía. El desarrollo de estas actividades exige contar con información actualizada, para lo cual se pueden desarrollar investigaciones específicas.

\section{Sobre las posibles líneas de investigación}

1. Realizar un catastro y análisis de los derechos humanos vinculados con los fenómenos de población y desarrollo que están contemplados en la legislación de los países latinoamericanos y caribeños, incluyendo la búsqueda de correspondencias entre los acuerdos que han suscrito los países y su implementación en los niveles nacionales. A partir de los derechos identificados, es preciso construir indicadores que permitan el monitoreo de los derechos humanos relativos a temas de población en los países de la región, considerando tanto la información disponible, como también la que sería necesario producir (hacer evidente esta necesidad es también promover los derechos humanos en población). La construcción de indicadores de derechos humanos en población implica recurrir a los indicadores tradicionales del campo de la población, pero implica también incluir en una parte importante-sino mayoritaria- indicadores cualitativos. Esto requiere ampliar las miradas, introducir nuevas perspectivas y desplegar destrezas y competencias no tradicionales, lo que ciertamente puede generar las resistencias propias al cambio que se dan en cualquier disciplina, organización o proceso social. 2. Realizar un estudio sobre el estado del arte de las organizaciones no gubernamentales que trabajan los temas de población y derechos humanos en los países de la región. Esto permitirá identificar el grado de avance en la materia, las metodologías empleadas y las aproximaciones teóricas. Así mismo, contribuir a la formación de redes de las organizaciones que trabajan el tema, e identificar contrapartes para las actividades de advocacy.

3. Analizar las políticas y programas de población que están implementándose en países de la región, desde la perspectiva de derechos humanos, lo que posibilitaría un diagnóstico del tratamiento del tema a nivel regional, como también la 
identificación de buenas prácticas o sugerencia de recomendaciones para mejorar la inclusión de los derechos humanos.

4. Revisar la normativa y la legislación referidas a las Comisiones Nacionales de Ética o Bioética en los países que cuenten con ellas, poniendo énfasis en el tratamiento de los temas de población, en particular de la investigación biomédica.

5. En relación con la fecundidad: a) evaluar la situación de los derechos reproductivos en los países de la región, complementando o continuando el trabajo de seguimiento de la CIPD: indagar sobre los avances en la legislación referida a la reproducción médicamente asistida, diagnóstico prenatal e investigación en embriones. También, reflexionar y proponer un marco para abordar los derechos reproductivos y sexuales de los adolescentes, incluyendo un análisis de la legislación y normativa en los países de la región; b) analizar la legislación, normativa y práctica del aborto inducido en los países latinoamericanos y caribeños, asumiendo el aborto desde una perspectiva de derechos; y c) realizar un análisis de situación y proponer guías para los procesos de consentimiento informado en atención y consejería en salud sexual y reproductiva a nivel regional.

6. Respecto de la mortalidad: a) sistematizar la conceptualización del derecho a la salud en la legislación de los países de la región y su relación con el acceso a los servicios de atención de salud, lo que puede hacerse profundizando el trabajo que la ops y la oms han desarrollado en este campo; b) analizar la situación y posibilidades de los derechos humanos de los enfermos terminales en América Latina y el Caribe, discutiendo los temas de cuidados paliativos y eutanasia y su relación con las particularidades culturales e históricas de los países de la región; c) analizar la situación de las personas enfermas y portadoras de VIH/SIDA en los países de la región, incluyendo su acceso a servicios de salud, su situación sociodemográfica y de participación en investigaciones, y las normativas y reglamentos existentes para estas personas y sus condiciones de aplicabilidad.

7. Indagar sobre la situación de la discusión referida a la Convención sobre la Protección de los Derechos de Todos los Trabajadores Migratorios y de sus Familiares en los países de la región, identificando los factores que impiden o retrasan su ratificación, es otro paso necesario, además de analizar la observancia de la MWC en los países latinoamericanos y caribeños que la han ratificado, incluyendo la descripción de la situación de los inmigrantes en tales países.

8. Por último, desarrollar estudios orientados a abordar la desigualdad sociodemográfica y la pobreza, a la luz del ICCPR y el ICESCR, como también desde la óptica de los Objetivos del Milenio, lo que puede hacerse incluso con los estudios e información disponibles. En la misma línea, desarrollar estudios para grupos especiales incluyendo los temas de género, minorías étnicas, migrantes internacionales, adultos mayores, personas viviendo con VIH/SIDA y violencia contra la mujer. 
Abramovich, V. (2004), Una aproximación al enfoque de derechos en las políticas y estrategias de desarrollo de América Latina, documento presentado en "Derechos y Desarrollo en América Latina: Una reunión de trabajo", Santiago de Chile, 9 al 10 de diciembre, [en línea] http://www. iadb.org/sds/SOC/publication/gen_2547_3973_s.htm.

Annan, K. (1997), "Carta de Envío”, Renovación de las Naciones Unidas: un programa de reforma. Informe del Secretario General (A/51/950), Quincuagésimo primer período de sesiones, Nueva York, Naciones Unidas, [en línea] http://www.un.org/spanish/docs/cover.htm.

Artigas, C (2003), La incorporación del concepto de derechos económicos, sociales y culturales al trabajo de la CEPAL. Reseña de algunas lecturas pertinentes, serie Políticas Sociales $\mathrm{N}^{\mathrm{o}} 72$ (LC/L.1964-P/E), Santiago de Chile. Publicación de las Naciones Unidas, No de venta: S.03. II.G.123.

(2001), El aporte de las Naciones Unidas a la globalización de la ética. Revisión de algunas oportunidades, Serie Políticas Sociales N 54 (LC/L.1597-P/E), Santiago de Chile. Publicación de las Naciones Unidas, $\mathrm{N}^{\circ}$ de venta: S.01.II.G.128.

Ballarín, P. y otros (1997), Las mujeres en la Unión Europea, Proyecto Piloto Erasmus (№ 26394MG2-196-1-ES-ERASMUS-EEM), Red de Estudios de las Mujeres, Universidad de Granada (España), Universidad de Leeds Metropolitan (Reino Unido), Universidad de Toulouse-Le Mirail (Francia) y Universidad de Helsinki (Finlandia), [en línea] http://www.helsinki.fi/science/ xantippa/wes/wes20.html.

Bobbio, N. (1993), Igualdad y libertad, Barcelona, Ediciones Paidós.

Carrozza, P. (2003), "From conquest to constitutions: retrieving a Latin American tradition of the idea of human rights", Human Rights Quarterly 25, pp. 281-313, Baltimore (Estados Unidos), The Johns Hopkins University Press.

Cassese, A. (1993), Los derechos humanos en el mundo contemporáneo, Barcelona, Editorial Ariel.

CEPAL (Comisión Económica para América Latina y el Caribe) (2005), Panorama Social de América Latina 2004 (LC/L.2220-P/E), Santiago de Chile. Publicación de las Naciones Unidas, $\mathrm{N}^{\mathrm{o}}$ de Venta: S.04.II.G.148.

(1996), América Latina y el Caribe quince años después. De la década perdida a la transformación económica, 1980-1995, Fondo de Cultura Económica, CEPAL, Santiago de Chile.

Ferrer, M. (2005), "La población y el desarrollo desde un enfoque de derechos humanos: intersecciones, perspectivas y orientaciones para una agenda regional”, Serie Población y Desarrollo, No. 60, CEPAL - Centro Latinoamericano y Caribeño de Demografía (CELADE) - División de Población. Santiago de Chile, noviembre de 2005.

Gostin, L. (2003), "Public health ethics: tradition, profession and values", Acta Bioethica, Año IXNo.2-2003, Santiago, Chile, OPS/OMS.

(2001), "Public health, ethics and human rights: A tribute to the late Jonathan Mann", The Journal of Law, Medicine \& Ethics, Volume 29:2, Summer 2001, pp. 121-130.

Hierro, L. (2002), "El concepto de justicia y la teoría de los derechos", en Díaz, E. y J. L. Colomer (eds.), Estado, justicia, derechos, Madrid, Alianza Editorial, pp. 11-74.

Hottois, G. (2000), "Bioética y derechos humanos", en Escobar, J. y otros, "Bioética y derechos humanos", colección Bíos y Ethos, Bogotá, Ediciones El Bosque.

Moravcsik, A. (1998), Explaining the Emergence of Human Rights Regimes: Liberal Democracy and Political Uncertainty in Postwar Europe, Working Papers, Weatherhead Center for International Affairs, Harvard University, [en línea] http://www.ciaonet.org/wps/moa02/, consultado el 16 de septiembre del 2004.

Muguerza, J. (2004), “Cosmopolitismo y derechos humanos”, en Serrano, V. (ed.), Ética y globalización. Cosmopolitismo, responsabilidad y diferencia en un mundo global, Madrid, Biblioteca Nueva, pp. 83-110.

Naciones Unidas (2003), “Discriminación contra la mujer: la Convención y el Comité,, Folletos informativos sobre los derechos humanos, $\mathrm{N}^{\circ} 22$, Nueva York. 
(2000), Declaración del Milenio (A/RES/55/2), Resolución aprobada por la Asamblea General, Nueva York.

(1997), Renovación de las Naciones Unidas: un programa de reforma. Informe del Secretario General (A/51/950), Quincuagésimo primer período de sesiones, tema 168 del programa, Nueva York, [en línea] http:/www.un.org/spanish/docs/cover.htm.

(1996), "Los derechos de los trabajadores migratorios", Folletos informativos sobre los derechos humanos, $\mathrm{N}^{\circ} 24$, Nueva York.

(1993), Declaración y Programa de Acción de Viena (A/CONF.157/23), Asamblea General, Conferencia Mundial de Derechos Humanos, Viena, 14 al 25 de junio.

(1991a), "Derechos Civiles y Políticos: el Comité de Derechos Humanos", Folletos informativos sobre los derechos humanos, No 15 , Nueva York.

(1991b), Principios de las Naciones Unidas a favor de las Personas de Edad, Resolución 46/91 de la Asamblea General de las Naciones Unidas, 16 de diciembre, [en línea] http://www.un.org/ spanish/envejecimiento/principios.htm.

(1986), Establecimiento de normas internacionales en materia de derechos humanos, Resolución de la Asamblea General, $41^{\circ}$ Período de Sesiones, 41/120, Nueva York, [en línea] http://www. un.org/spanish/documents/ga/res/41/list41.htm.

(1968), Proclamación de Teherán, (A/CONF. 32/41 at 3).

(1948), Declaración Universal de Derechos Humanos, (A/RES.217 A III) [en línea] http://www. unhchr.ch/udhr/lang/spn.pdf.

(1945), Carta de las Naciones Unidas, [en línea] http://www.un.org/aboutun/charter.

OACDH (Oficina del Alto Comisionado para los Derechos Humanos) (2004), Los derechos humanos y la reducción de la pobreza. Un marco conceptual (HR/PUB/04/01), Nueva York y Ginebra.

OEA (Organización de Estados Americanos) (2003), Programa Interamericano para la Promoción y Protección de los Derechos Humanos de las Personas Migrantes en el Marco de la Organización de los Estados Americanos (CP/CAJP-2038/3), Consejo Permanente, Comisión de Asuntos Jurídicos y Políticos.

Perley, S. y otros (1992), “The Nuremburg Code: An international overview”, en: Annas, George y M. Grodin (eds.), The Nazi Doctors and the Nuremburg Code: Human Rights in Human Experimentation, Nueva York, Oxford University Press, p. 158.

PNUD (Programa de las Naciones Unidas para el Desarrollo) (2004), Informe sobre el desarrollo humano 2004. La libertad cultural en el mundo diverso de hoy, [en línea] http://hdr.undp.org/reports/global/2004/espanol/.

(2000), Informe sobre el Desarrollo Humano 2000. Derechos Humanos y Desarrollo Humano: en pro de la Libertad y la Solidaridad, [en línea] http://www.undp.org/hdr2000/spanish/HDR2000. html.

Rodríguez, L. (2002) "El debate sobre los derechos de grupo", en Díaz, E. y J. L. Colomer (eds.), Estado, justicia, derechos, Madrid, Alianza Editorial, pp. 409-430.

Sass, H. (1983), "Reichsrundschreiben 1931: Pre-Nuremburg German regulations concerning new therapy and human experimentation”, Journal of Medicine and Philosophy 8, pp. 99-111.

Singer, P. (2003), Un solo mundo. La ética de la globalización, Barcelona, Editorial Paidós.

Sumner, L. W. (2001), "Rights", en LaFollete, H. (ed.), The Blackwell Guide to Ethical Theory, Blackwell Philosophy Guides, Estados Unidos, Blackwell Publishers, pp. 288-305.

UNFPA (Fondo de Población de las Naciones Unidas) (2004), Estado de la población mundial 2004, [en línea] http://www.unfpa.org/swp/2004/espanol/ch1/page5.htm.

United Nations (1996), "The Committee on Economic, Social and Cultural Rights (Rev. 1)", Fact Sheet $N^{\circ} 16$ (Rev. 1), Nueva York.

(1990), Population and Human Rights (ST/ESA/SER.R/107), Department of International Economic and Social Affairs, Nueva York.

Wellman, C. (1995), "Rights: systematic analysis", en Reich, W. (ed.), Encyclopedia of Bioethics. Revised Edition, Estados Unidos, Simon \& Schuster Macmillan, pp. 2305-2310. 